\title{
Phosphatide patterns of bone marrow
}

Recent investigations demonstrated significant differences to exist in the composition of the phosphatides and their fatty acid constituents between erythrocytes of different species of mammals ${ }^{1-5}$. In the animal series: rat, rabbit, man, pig, cow and sheep the lecithin content of the red-cell phosphatides was found to decrease from about 58 to about $\mathbf{I} \%$, while the sphingomyelin content increased concomitantly in that order $^{5}$. No information is available concerning the background of this remarkable difference in erythrocytes from various species. Since the erythrocyte membranes are constituted in the hematopoietic bone marrow and data about the phosphatides of this origin are scant $y^{6-8}$, comparative analyses were made into the bone marrow of several animals differing with respect to the composition of their erythrocyte phosphatides.

Samples were investigated of fresh red bone marrow from rabbit, cow and sheep. After bleeding of the rabbits the femur was dissected and the red marrow extirpated. An amount of $2 \mathrm{~g}$ of this material was extracted twice with $50 \mathrm{ml}$ of ethanol - ether $(3: I, v / v)$ in a nitrogen atmosphere. In the case of the cow and sheep parts of vertebrae containing red marrow (free of spinal marrow) were collected within 20 min after killing of the animals and extracted with ethanol-ether in a similar way. In accordance with other reports on the lipids of human and rabbit bone marrow, the phosphatide content of the studied materials was rather $l o w^{\mathbf{8}, 9}$. In the red-marrow samples of the rabbit the phosphatide percentage was about $\mathrm{I} \%$ of total lipids, while in the cow marrow a value of $4 \%$ was found. It should be noted that yellow marrow obtained from the distal part of the tibia from rabbits and the humerus of cows only contained very small amounts of phosphatides (less than $0 . \mathrm{\%} \%$ of total lipids).

Because of the preponderance of neutral lipids, a separation of the lipids and the phosphatides (from red marrow) was made beforehand by chromatography on silicic acid columns ${ }^{5}$. Determinations of the major individual types of phosphatides were carried out by chromatographic procedures essentially identical to those described for the analysis of erythrocytes ${ }^{5}$.

The results of these preliminary experiments compiled in the accompanying table indicate that the composition of the phosphatides in the red marrow of rabbit, cow and sheep do not reflect the marked differences found in this respect between the circulating erythrocytes of these species. Lecithin was found to be quantitatively the major phospholipid of the red bone marrow of all three animals studied. With respect to the lecithin content, constituting only about $\mathrm{I}$ and $5 \%$ in the erythrocytes of sheep and cow, respectively, there is a significant difference between circulating red cells and the hematopoietic bone marrow. Owing to the heterogeneity of the cell population in the bone marrow, the available data apparently do not allow the conclusion to be drawn that differences exist in the phosphatide composition between circulating erythrocytes and their immature stadia present in the marrow. The red bone marrow is known to contain roughly three times as much leucocytes and prestadia as erythroblasts ${ }^{10}$, in contrast to the circulating blood cells which show a significant domination of erythrocytes. Preliminary experiments performed on leucocytes isolated from cow blood showed a markedly higher percentage of lecithin to be present in these cells than in the erythrocyte fraction. Theories attempting to describe the formation of the various types of blood cells have to take into account 
TABLE I

COMPOSITION OF MAJOR PHOSPHATIDES FROM RED BONE MARROW AND DISTRIBUTION OF RADIOACTIVITY AFTER AN INCUBATION in vitro WITH RADIOACTIVE PHOSPHATE

Data are given as percentages of total phosphatides and percentages of total radioactivity, respectively. The standard errors are placed between parentheses.

\begin{tabular}{|c|c|c|c|c|c|}
\hline Animal & $\begin{array}{l}\text { Number of } \\
\text { analysis }\end{array}$ & Lysolecithin & $\begin{array}{c}\text { Sphingomyelin } \\
(\%)\end{array}$ & $\begin{array}{c}\text { Lecithin } \\
(\%)\end{array}$ & $\begin{array}{c}\text { Phosphatidyl } \\
\text { ethanolamine } \\
(\%)\end{array}$ \\
\hline \multicolumn{6}{|l|}{ Rabbit } \\
\hline Composition & 4 & $5(5)$ & $23(4)$ & $55(5)$ & I7 (4) \\
\hline Radioactivity $^{\star}$ & 3 & & & $80(10)$ & $7(4)$ \\
\hline \multicolumn{6}{|l|}{ Cow } \\
\hline Composition & 4 & $7(2)$ & $23(4)$ & $5 \mathrm{I}(4)$ & I9 (4) \\
\hline Radioactivity" & 3 & & & 90 (IO) & $5(5)$ \\
\hline \multicolumn{6}{|l|}{ Sheep } \\
\hline Composition & 3 & 3 & $24(4)$ & $57(4)$ & I6 (4) \\
\hline Radioactivity $^{\star}$ & I & & & 90 & 5 \\
\hline
\end{tabular}

* The radioactivity recovered from minor components of the bone-marrow phosphatides - phosphatidyl inositol and phosphatidic acid - amounted to $5 \%$ for rabbit and sheep and $13 \%$ for cow marrow.

this remarkable difference in phosphatide composition of red and white cells in several animal species.

Although in the bone marrow the leucocytes exceed in number the erythrocytes, the production and extrusion of the erythrocytes is known to be significantly greater than that of the leucocytes ${ }^{10}$. In this respect it was thought to be of interest to obtain information about the dynamic state of the individual phosphatides in the bone marrow of various animals producing erythrocytes having a different phosphatide composition. Red bone-marrow cells from the three animal species under discussion were incubated in vitro in 2 vol. of Krebs-Ringer solution containing $20 \mu \mathrm{C} / \mathrm{ml}$ of radioactive orthophosphate. After an incubation period of $5 \mathrm{~h}$ the lipids were extracted from the cells according to the method of BLIGH AND DYER ${ }^{11}$. After a chromatographic separation of neutral lipids and phosphatides the distribution of the radioactivity among the individual types of the latter class was determined on silica paper chromatograms, and occasionally on chromatograms of the water-soluble phosphodiesters prepared by alkaline saponification of the phosphatides. The results demonstrated that under the conditions used the radioactive phosphate was incorporated mainly into the lecithin of the bone-marrow cells of the animal species studied (Table I). An experiment in vivo performed by injection of radioactive phosphate into the femur of a rabbit ${ }^{12}$ after a 5 -h period also showed the lecithin of the red bone marrow to contain the highest amount of radioactivity. These results are consistent with those of THOMPSON AND HANAHAN ${ }^{13}$, who observed recently that lecithin is the major phosphatide of bovine hematopoietic red marrow, and who recovered after an incubation in vitro with $\left[6-{ }^{14} \mathrm{C}\right]$ glucose the highest percentage of radioactivity in the lecithins.

Apparently metabolically active lecithin is abundant in the red bone marrow, also of those animal species showing an extremely low content of lecithin in their circulating erythrocytes. It is intriguing how red-cell membranes deprived of or poor 
in lecithin are constituted in a lecithin-rich environment. Studies on this problem and on the origins of the difference in fatty acid composition ${ }^{2}$ and plasmalogen concentration between erythrocytes of different animal species are in progress.

This investigation was supported by the Netherlands Organization of Pure Research (Z.W.O.). The authors wish to thank Drs. D. J. HANAHAN and G. A.Thompson (Department of Biochemistry, University of Washington, Seattle, Wash.) for fruitful discussions.

$\begin{array}{cl} & \text { E. MULDER } \\ \text { Department of Biochemistry, Laboratory of Organic Chemistry, } & \text { J. DE GIER } \\ \text { State University of Utrecht, Utrecht (The Netherlands) } & \text { L. L. M. VAN DEENEN }\end{array}$

1 J. C. Turner, H. M. Anderson and C. P. Gandal, Biochim. Biophys. Acta, 30 (1958) 130.

2 F. Kögl, J. de Gier, I. Mulder and L. L. M. van Deenen, Biochim. Biophy's. Acta, 43 (1960) 95.

3 D. J. Hanahan, R. M. Watts and D. Pappajohn, J. Lipid Research, I (1960) 421.

4 R. M. C. Dawson, N. Hermington and D. B. Lindsay, Biochem. J, 77 (1960) 226.

5 J. de Gier and L. L. M. van Deenen, Biochim. Biophys. Acta, 49 (I96I) 286.

- A. A. Dietz, J. Biol. Chem., 165 (1946) 505.

7 H. E. Newlin and C. M. McCAy, Arch. Biochem., 17 (1948) I 25.

${ }^{8}$ E. F. Elko and N. R. DiLuzro, Radiation Research, i i (1959) I.

9 P. K. Lund, D. M. Abadi and J. C. Mathies, J. Lipid Research, 3 (I962) 95.

$10 \mathrm{~K}$. RoHr, Das menschliche Knochenmark, Georg Thieme Verlag, Stuttgart, I960.

11 E. S. Bligh and W. J. Dyer, Can.J. Biochem. Physiol., 37 (I959) 9 II.

12 E. L. McCandless and D. B. Zilversmit, Acta Physiol. Pharmacol. Neerl., 5 (1956) 98.

13 G. A. Thompson and D. J. Hanahan, Arch. Biochem., 96 (1962) 67 I.

Received April 9th, I962

Biochim. Biophys. Acta, 59 (1962) 502-504

\section{The characterization and biosynthesis of an $\mathbf{N}$-methylethanolamine phospholipid from Clostridium butyricum}

Several laboratories have recently presented evidence in support of phosphatidyl mono- and dimethylethanolamine as precursors of lecithin in animals ${ }^{1-4}$ and in Neurospora crassa ${ }^{5}$ although the relative contributions of this pathway and the cytidine-dependent pathway to lecithin synthesis are still in doubt ${ }^{6}$. Lecithin has been observed in relatively few bacteria ${ }^{7,8}$ and little is known about its biosynthesis in these organisms. Studies in this laboratory on the structure and metabolism of the lipids of Clostridium butyricum, an organism that does not synthesize lecithin*, have revealed the presence of a monomethylethanolamine phospholipid.

C. butyricum was cultured and harvested by methods previously described ${ }^{9}$. The amino acid supplement of HENDERSON AND SNELL ${ }^{10}$ was added to the medium at one-half the concentrations indicated in their paper. Extraction and isolation of lipids have also been described ${ }^{9}$.

In addition to phosphatidyl ethanolamine, a second major phospholipid peak was observed when the lipids of $C$. butyricum were chromatographed on silicic acid by the method of WREN ${ }^{11 *}$. This peak emerged after phosphatidyl ethanolamine.

\footnotetext{
${ }^{*}$ H. GoldFine, unpublished experiments.
} 